Review

\title{
Maternal and child health in Bangladesh: a critical look at the policy and the sustainable development goals
}

\author{
Nur Newaz Khan ${ }^{*}$ \\ Department of Political Science and Sociology, North South University, Bangladesh \\ *Corresponding author: Nur Newaz Khan, Lecturer, Department of Political Science and Sociology, North \\ South University, Bangladesh. Phone: +8801816862112; E-mail: nur.khan@ northsouth.edu; \\ newaznur@gmail.ocm
}

Received: 07 August 2017/Accepted: 04 September 2017/ Published: 28 September 2017

\begin{abstract}
Based on secondary analysis, this paper places a critical discussion looking back in history of maternal health achievements by Bangladesh, future adaptability and potentials forwarding to the sustainable development goals (SDGs) set by United Nations. Since the transition from MDGs to SDGs, Bangladesh achieved a many progress in maternal health development but still grappling with many structural and cultural barriers. Implementation of policy documents in community level, lack of better infrastructure, health bureaucracy induced delays, culture of absenteeism among practitioners and lack good health governance are some major challenges still hindering a fostered progress in achieving the expected improvement in maternal and child health condition in community and broader level. Evidences discussed in this paper suggests that, the clauses related to implementation and maintenance need to be stronger in the maternal health policy for future direction and sustainable progress in maternal health. The policy should act in practice, not as a document, to improve maternal health and reducing mortality that would finally speed up the progress in achieving SDGs target in more pragmatic sense.
\end{abstract}

Keywords: maternal health; child health; Bangladesh; sustainable development goals; health policy

\begin{abstract}
1. Introduction
Bangladesh is one of the developing countries who signed onto achieving the Sustainable Development Goals (SDGs). In the new target of SDGS the issue of maternal is fitting under goal number three; Good health and well-being which was targeted under fifth goal in pervious Millennium Development Goals (MDGs) framework. Over the last two decades, national health policy and strategies progressed with significant achievements. As a part of national health policy, Bangladesh government developed National Maternal Health Strategies, which incorporates a broader approach from rights' perspective for safer motherhood and included in different health and population sector programmes. Still now, Bangladesh is aiming to reduce maternal and child morbidity through this renovation process. United Nations Population Fund (UNFPA), and the Maternal Death and Disability prevention programmes (both government and non-government sectors) are working with existing facilities and resources. This essay is an attempt to have a critical look and analyze existing health policy regarding maternal mortality and achievements and gaps or barriers within the policy. An overview of Bangladesh health care systems will lead the discussion to figure out the scope of maternal health policy within the existing health structure following description on so far achievements in regards to maternal health and meeting SDGs. The latter section will discuss on existing evidences of good policy implementations regarding maternal health and mortality. A critical look on gaps and barriers of this policy will try to locate cotemporary importance relating to maternal health policy application in Bangladesh.
\end{abstract}




\section{Health care system and maternal health care in Bangladesh}

Bangladesh is located in South Asia encompassing a 147,570 square kilometers area with around 142 million populations and 964.42 persons per square kilometer; for the administrative structure, the country is divided into 6 divisions, 64 districts, 496 Upazilas (formerly called Thanas), 4,451 unions and 13,500 wards(Bangladesh Bureau of Statistics, 2012).In Bangladesh, the health care service and system is complex of different initiatives; public, private and NGO healthcare are major. Informal practitioners also cover a notable portion of health care. Government is the central actor in country's health system and public health care service is foremost and stronger in sense of infrastructure. However, private sector is playing supplementary and often competitive role in health sector with public one. NGOs also have a significant role providing primary, reproductive and family planning services and sometime influencing government's strategy in adopting models of health care delivery. All these different streams of health care systems are under control of the government through ministry of health and the policy guidelines (Osman, 2004). Bangladesh adopts many changes considering social determinants of health (Marmot and Wilkinson, 2005) in harmony with local and global modifications in public health.

At the macro level the Ministry of Health and Family Welfare (MOHFW) is the key decision maker and responsible for health policy design, planning. There are two execution arms under MOHFW: the Directorate General of Health Services (DGHS) and Directorate General of Family Planning (DGFP). The DGHS is providing technical guidance to the ministry and responsible for implementation of all health programmes. The DGFP is for Family Planning (FP) programme implementation. Bangladesh government manages and controls the greatest part of the health infrastructure and health care system. To serve the 4,470 unions at the local level, 3275 Union Health and Family Welfare Centers (UHFWCs) established. Additionally there are Upazila Health Complexes in 391 rural Upazilas, 64 district hospitals, 13 government medical college (MC) hospitals, 6 postgraduate hospitals and 25 specialized hospitals. There are also a further 54 Maternal and Child Welfare Centers (MCWCs) established to provide maternal health services at the district and Upazila level. Most recently, the government has taken another initiative to construct a Community Clinic (CC) at the village level for every six thousand population(Bangladesh Ministry of Health and Family Welfare, 2000). The health service delivery system in the public sector is divided into primary, secondary, and tertiary levels. At all level, maternal and child health care is the priority in policy and implementation to achieve the SDG target.

\section{Development of maternal health care policy and current achievement}

The activities of population programme in Bangladesh started during early 1950s from a small clinic-based initiative by health professionals and social worker. A platform was established as Family Planning Association of Bangladesh (FPAB) and the government in 1958 recognized the voluntary activities of this FPAB. Following this initiative, in 1960, the government established the Directorate of Family Planning and began their first national FP programme (MOHFW, 2000).

In following decades, Bangladesh government's policy had to concentrate on reduction of population growth; policy perceived that a consistent maternal and child health based family planning programme would help to achieve development goals (Rahman et al., 2003). NGOs interventions provided significant policy recommendation based on their programme and research. The country experienced a promising change in population control and fertility rate in 1990s (NIPORT et al., 2003).

For a future direction the Health and Population Sector Strategy (HPSS) was developedin1997, which aims at an integrated service through system to ensure one-stop full-range of necessary reproductive health and family planning services. The following seven strategies were included in the HPSP (MOHFW, 1998):

a) Focus on Emergency Obstetric Care for reducing maternal mortality,

b) Provision of Essential Obstetric Care/Basic maternity care services for promotion of "good practices" including early detection and appropriate referral of complications

c) Addressing the needs of women through a woman friendly hospital initiative

d) Communication for behavior change and development

e) Involvement of professional bodies

f) Stakeholder participation

g) Promotion of innovation [other new approaches]

This was a shift from health worker based system to a fixed community clinic approach and the series of these interventions aimed to reduce maternal mortality. This approach focused on essential and emergency obstetric maternal care service for the first time in policy and implementation. In addition, with this HPSP, government published the Bangladesh National strategy for Maternal Health in October 2001. This policy document is theoretical framework of what is necessary and expected for improvement of maternal health situation in national level. It includes some of the previous provision and new maternal services such as emergency obstetric 
care, antenatal care, skilled attendance, postnatal care, family planning, and services for women and girls subject to violence with necessary referral systems and human resource requirements. However, less focus is given on particular implementation processes of these (Rahman et al., 2003).

According to the website of the United Nations Development Programme (UNDP), maternal health situation in Bangladesh progressed significantly over last twenty years. During 1990, the first SDG progress report showed that, the maternal mortality ratio as 574 per 100,00 live births in Bangladesh. There is a rapid increase in this achievement recently; according to Bangladesh Maternal Mortality Survey (BMMS), the ratio declined from 322 in 2001 to 194 in 2010, within nine years a 40 percent declined. For achieving SDGs in 2015, the average annual rate of reduction is 3.0 percent whereas, the average reduction rate achieved 3.3 percent per year in Bangladesh. Reduced fertility rate (from 5 births per woman in 1990, to 2 in 2011) and increased skilled delivery attendance (from 5\% in 1991 to $32 \%$ in 2011) were reported to be the associated reasons behind this decline (MOHFW et al., 2015).

\section{Maternal health service mechanism; evidence based policy reform}

In public health sector, the maternal health service is provided by government network based facilities and resource centers through different level of administration. The Family Welfare Assistants and Health Assistant from the Community Clinics are the root-level service providers governed by Union or urban health centers. The Maternal and Child care Centers (MCWC) provides only the maternal and child health services under the direct control of Directorate of Family Planning that are established mostly at the district level (with some also at the Upazila level). This is expected that these centers should be equipped to provide basic EOC and obstetric first aid (Ahmed et al., 1995). In addition to the Ministry of Health and Family Welfare, there are many government and non-government organizations and research institutes are involved in research and development on maternal health. Most of the activities are funded by international and bilateral organizations including WHO, UNFPA, UNICEF, UNDP, UNHCR, World Bank, ADB, and DFID etc. that are also playing important role in providing policy guidelines, implementation help, and ground work for improvement of the maternal health and overall health sector as well.

Achievements onto improved maternal health and reduced maternal mortality are related with some practical factors such as targeted public health, education, intervention, investment, and increased public expenditure on health. For example, stipend and other support in women education influence the immunization, family planning, and nutrition supplementation, oral rehydration solution (ORS) programme in rural and urban areas. Women education interventions contributed in increasing maternal health awareness that forced the policy reform; from single to multilevel or integrated policy implementation in family planning and maternal health. Both in government and non-government sector, interventions, and combined programme of poverty and health service create evidences that direct the policy change, reform and more inclusion of better concentration on maternal health. For instance, the emergency obstetric care and other related services were included after successful intervention of maternal health related programme. In policy level, non-government sector generate more evidences and force to change than government due to the political instability and commitment for longterm intervention in public health sector. For example, the one-stop community clinic mechanism of the government had a good public acceptance however, later maintenance of this did not continue with the same pace in both policy and practice.

Government EOC project is an effective way of delivering improved maternal health care. The programme included the renovations, better supplies of equipment in district hospitals, training and facilities in management level and monitoring, etc. The pilot programme got reputation among local community and contribute in reforming policy regarding maternal health care and practice (Hossain and Ross, 2006; Nasreen, 2006). This evidence proved that long-term results of the EOC initiative will depend on government's commitment to continue this in future that could reach the community maternal care (Nasreen et al., 2007) and thus the existing policy should be working however, requires a better implementation policy and execution.

Some non-governmental projects has been tested in small scale creating innovative models compared to public sector in improving maternal health care and related polices. A long term project of maternal and child health combined with family planning in one district level showed that the community/client oriented service is effective and could be successful even in unfavorable socioeconomic circumstances. One of the important features of this project is local female community health workers who were the beneficiaries. Well support of female paramedical and field supervisors, training on household communication, door step meetings, transport allowances, community midwife, trained physician and functional referral chain created a better environment for mothers to interact regarding their maternal and menstrual health needs (LeGrand and Phillips, 1996; Ronsmans et al., 2010). Projects in Matlab (rural area in south-east part of the country) also suggested that 
based on qualified community culture based interventions has more sustainable and raising the efficiency level more than the government programme (Rob and Cernada, 1992). Study findings from Matlab MCH-FP interventions revealed that family-planning programme could be successful. Particularly in Matlab, the clientoriented services delivered through the female community health workers $(\mathrm{CHW})$. In addition, this is observed that, the orientation of an organizational culture grounded on qualification and quality of care is more likely to be succeeded in improving the performance of the CHWs to levels developed than those of the Government programme. The design of self-referral in Matlab MCH-FP areas intensely recommends that if quality emergency obstetric services are accessible, significant numbers of people will use them, even in the nonappearance of community interventions inspiring use. In the same area, the ICDDR, B Extension Project shows higher rates contraceptive use, lower rate of maternal mortality and increased access to women's health compare to the national rate. The findings suggested that, the performance of the government programmes could be improved by designing simple interventions. Door to door visiting plan, motivating skills, community associations, referral and documentation are critical to the success or failure in large scale government programmes (Nasreen et al., 2007).

The Skilled Birth Attendants programme is evidence that contributed in maternal health policy particularly in training and budgeting for safer birth and motherhood. Most of the skill and training programme for traditional birth attendants by the government are limited in improving knowledge and skill but not connect with wider socio-cultural practice, ideology and norms, and bridging between traditional and modern practitioners (Ahmed et al., 2010). NGOs micro level programmes showed a better connection between formal health system and traditional birth attendants (TBA) training or skill enhancement through community based approach that could be much effective (Blum et al., 2006; WHO, 2004). These programmes are working through close collaborations with existing TBAs in community to train and increase safe delivery numbers, necessary referral and steps in complications (Cockcroft et al., 2004; Jahan, 2007). These evidences force the government maternal health policy in adoption of components that worked in these programmes. These evidences also reveal needs of scaling up those models and linkage with formal health care system for suitability in government health structure. Studies suggested, community participation along with TBA training programmes is necessary in government sector to respond quickly in complicated delivery cases (Paul and Rumsey, 2002). In a wider range, unsafe abortion is still prevalent due to lack of trained human resource and procurement supply (Akhter, 2001; Berer, 2009). There is a good partnership has been observed in MR programmes between government and NGOs where models exhibited that a small setup of trained personnel and supplies can increase safe abortion and physician observed referring to paramedics in MR centers. All these had have major policy implications in maternal and child health care in recent decades (Mannan et al.,2013).

NGOs community based participatory interventions utilize the community partnership in successful provision of different elements of maternal health. With lot of challenges BRAC health intervention in both rural and urban areas show promises to develop health cadres, nationwide implementation, and coordination with government facilitation programmes and significantly contribute in maternal health improvement. BRAC's programme design was based on widespread primary health care model. It was organized in a way to be combined with the rural development program and the non-formal primary education programme, as believed in addressing health and development issues comprehensively. Shasthya Shebikas or Community Health Volunteers are operating the health interventions integrated with MNCH interventions. The Shaystha Shebika (health worker) model that works in grassroots level with the community in delivering service and information actually influenced the government's policy regarding maternal health in reaching disadvantaged and poor people (Nasreen et al., 2007). Still with all the achievements and success, nevertheless, the maternal health policy has some gaps and challenges particularly in implementation.

\section{Gaps and barriers in current maternal health policy}

Policies are to determine the best alternative that will achieve the necessary goals a given population (Nagel, 1999). Approaches of WHO's public health policy is to set health as an agenda for policymaker in all sectors at all levels (WHO, 1999). However, health policy decisions could be highly political and not a rational process of discussion (Collins, 2005). For instance, although evidences show that the policy is having good provisions to the population health however, the question regarding maternal mortality is more related with implementation of the policy. It is the political environment that hindering to address and implement those things in the health policy regarding maternal health. The models using by NGOs are limited to small scale and need to be tested/replicated in countrywide range. Weaker implementation and monitoring policy and inconsistency in political commitments are affecting the development planning and policy implementation in maternal health 
sector (Chaudhury and Hammer, 2004; Hossain et al., 2007). This clearly reveals the necessity to look at gaps in between health policy and implementation in government health sector.

Analysis of evidences reveal that, the nature of service utilization is unequal in local government levels; there are underutilization of facilities in root level (below Upazila) and excess use in upper (district) level creates uneven distribution of services related to maternal health and emergency care but the policy focused less regarding this (Mahmud, 2004). Many report indicates to various issues related to emergency obstetric care in government maternal health centers such to the poor quality of service, shortage of equipment and medicines, low maintenance, reluctance for follow-up care., cost of complicated case for poor, prevalent absenteeism of medical staffs; these are less highlighted in related policy (Afsana, 2004; Nasreen et al., 2007).

As a policy document, the National Strategy for Maternal Health covers many of the areas that are recently identified in evidence-based researches and studies on maternal morbidity and health. The need of different service providers and training, cost, and budgeting, inadequacy of human resources are all important issues focused in the policy. However, the policy does not give stress on the capacity of local institutions to create skilled workforce and desire of profession. More specifically, workplace in rural or remote areas may not be expected for health workers to be placed. Moreover, the monitoring system is crucial to give more emphasis in policy as studies reported that double job or private practice of doctors is crating problem in effective maternal health service delivery (Afsana and Rashid, 2001; Gruen et al., 2002). Besides the achievements, still equal access to family planning, antenatal care, clean and safe deliver, emergency obstetric care are mostly not satisfactory (NIPORT et al., 2001; Pogge, 2004; Ronsmans et al., 2010) and so far the facilities available in government health centers are not properly utilized. The maternal health policy concentrates on developing obstetric and post-natal service in public hospitals but not assessing the essentials or requirements for poor or people who are living very remote areas. In some areas, the rural people are too far from services and lack emergency care. In urban areas, poor people have less access of health and service information compare to middle and upper economic class. Thus, the government funds, and the policy effectively discriminates against the uneducated, rural, and poor (Jahan, 2007; Nasreen et al., 2007).

The government is the central and obliged to improve the maternal health conditions in the country that is committed to several international agreements and national constitution. One of the major commitments is the United Nation's millennium development goals that place the reduction of maternal mortality. At the national level, the Constitution of the People's Republic of Bangladesh Section XVIII.1 states: "The state will consider it to be its prime obligation to ensure enhancement of nutrition level and public health of its citizens...". Some other laws are related to health service provision but the maternal health policy is too weak to address any dispute or negligence or malpractice in government health institutions and thus none of these make sure the right care to women during pregnancy and in post-natal stage (Chaudhury and Hammer, 2004; Hossain, 2009; Hossain et al., 2007; Mahmood, 2012; Vian, 2008).In addition to that, the policy gives less attention in scarcity of structural capacity for emergency obstetric care and trained staffs. Basic infrastructure like electricity supply is not steady that make difficult the effective service delivery in case of complicated pregnancy (Osman, 2008; Rashid et al., 2005).

Many socio-cultural factor are not addressed in maternal health related policy such as perceptions, gender norms, cultural beliefs that hinder women's access to the health and services. The weak infrastructure and lack of accessible quality services obstructs the right of pregnant women to get opportune and appropriate health care. Early pregnancy and motherhood is resulting more incidents of complications in giving birth. Religious and cultural beliefs regarding pregnancy and childbirth can hinder women's access to medical care. Even domestic violence is one of reasons of maternal death with $14 \%$ of reporting in studies (Asling-Monemi et al., 2009; Silverman et al., 2009) that is quiet alarming but all these are not adequately addressed in maternal health policy. The high prevalence of domestic violence against women unduly affects pregnant women. The government policy fails to coordinate medical, judiciary, and police services to combat domestic violence problem. The policy is weak in dealing with behavior of the community such as decision making to participate in clinical setup; for example, establishment of community clinics by government lacks community involvement. One of the reasons is that, often these clinic projects are influenced by political decisions that found to be counterproductive. Lack of coordination with UHFWCs at union level was a major obstacles and non-involvement of community group was found to be a reason for the failure of functioning of the community clinics (Ssengooba et al., 2007).

\section{Conclusions}

Development and structure of the maternal health policy in Bangladesh and evidences evaluating the policy strength analyzed in this essay. All the evidences discussed above reveal that different models of maternal 
health services in Bangladesh guided the policy reform in achieving the global target of SDGs. Onto that path, Bangladesh experienced a slow progress due to lack of stronger policy provisions of management and resource utilization in government health sector. There are evidences of effective maternal health care and emergency service delivery from non-government health projects but replication in government sector is facing lack of economic resources and political commitment. The policy is good in the sense of its adaptive nature; government adopts good practices most of the time into the policy. However, sustainability and maintenance is always the issue that is not under control as per the policy of maternal health in public sector. The contemporary important aspect of the maternal health policy is to keep the existing achievements sustainable that also require a favorable political enabling environment to adopt good practices in public health service arena. The health policy should be integration oriented and collaborative with non-government sector as evidences show that, community approach could be adopted in regional health centers. Evidences also reveal that, for future direction and sustainable progress in maternal health, the clauses related to implementation and maintenance needs to be stronger in the maternal health policy. The policy should act in practice, not as a document, to improve maternal health and reduce mortality that would finally speed up the progress in achieving SDGs target.

\section{Conflict of interest}

None to declare.

\section{References}

Afsana K, 2004. The tremendous cost of seeking hospital obstetric care in Bangladesh. Reprod. Health Matters, 12: $171-180$.

Afsana K and SF Rashid, 2001. The challenges of meeting rural Bangladeshi women's needs in delivery care. Reprod. Health Matters, 9: 79-89.

Ahmed SM, A Hossain, MA Khan, MK Mridha, A Alam, N Choudhury, T Sharmin, K Afsana and A Bhuiya, 2010. Using formative research to develop $\mathrm{MNCH}$ programme in urban slums in Bangladesh: experiences from MANOSHI, BRAC. BMC Public Health, 10: 663.

Ahmed YH, MH Rahman, FK Chowdhury, YA Khan and HH Akhter, 1995. Baseline survey for assessment of emergency obstetric care services in Bangladesh, Bangladesh Institute for Promotion of Essential and Reproductive Health Technologies (BIRPERHT), Dhaka.

Akhter HH, 2001. Mid level provider in menstrual regulation: Bangladesh experience. Proceedings of the Conference on Expanding Access: Advancing the roles of midlevel providers in menstrual regulation and elective abortion care, 02 December 2001, South Africa, pp. 2-6.

Asling-Monemi K, RT Naved and LA Persson, 2009. Violence against women and the risk of fetal and early childhood growth impairment: a cohort study in rural Bangladesh. Arch. Dis. Child., 94: 775-779.

Bangladesh Bureau of Statistics, 2012. Bangladesh population and housing census 2011. Ministry of Planning, Dhaka.

Berer M, 2009. Provision of abortion by mid-level providers: international policy, practice and perspectives. Bull. World Health Organ., 87: 58-63.

Blum LS, T Sharmin and C Ronsmans, 2006. Attending home vs. clinic-based deliveries: perspectives of skilled birth attendants in Matlab, Bangladesh. Reprod. Health Matters., 14: 51-60.

Chaudhury N and JS Hammer, 2004. Ghost doctors: absenteeism in rural Bangladeshi health facilities. World Bank Econ. Rev., 18: 423-441.

Cockcroft A, D Milne and N Andersson, 2004. Bangladesh Health and Population Sector Programme, 19982003: The Third Service Delivery Survey, 2003. CIET Canada and Ministry of Health and Family Welfare, Government of the People's Republic of Bangladesh.

Collins T, 2005. Health policy analysis: a simple tool for policy makers. Public Health, 119: 192-196.

GruenR, R Anwar, T Begum, JR Killingsworth and C Normand, 2002. Dual job holding practitioners in Bangladesh: an exploration. Soc. Sci. Med., 54: 267-279.

Hossain J and S Ross, 2006. The effect of addressing demand for as well as supply of emergency obstetric care in Dinajpur. Bangladesh. Int. J. Gynaecol. Obstet., 92: 320-328.

Hossain N, 2009. Rude Accountability in the Unreformed State: Informal Pressures on Frontline Bureaucrats in Bangladesh. IDS Working Papers, 2009(319), 01-35.

Hossain N, Ru Zaman, N Banks and CH Geirbo, 2007. The Incentives and Constraints of Government Doctors in Primary Healthcare Facilities in Bangladesh. Research and Evaluation Division, BRAC, Dhaka.

Jahan R, 2007. Securing maternal health through comprehensive reproductive health services: lessons from Bangladesh. Am. J. Public Health, 97: 1186. 
LeGrand TK and JF Phillips, 1996. The effect of fertility reductions on infant and child mortality: Evidence from Matlab in rural Bangladesh. Popul. Stud., 50: 51-68.

Mahmood SAI, 2012. Editorial: Health Systems in Bangladesh. Health Syst. Policy Res., Aug 18; 1(1).

Mahmud S, 2004. Health and Population: Making Progress under Poverty. Econ. Polit. Wkly., Sep 4:4081-92.

Mannan M, R Huque, SZ Islam and H Ahmed, 2013. Impact Evaluation of Strengthening the National MR Programme in Bangladesh. Report prepared for Policy and Operations Evaluation Department Ministry of Foreign Affairs, the Netherlands Bangladesh Institute of Development Studies (BIDS), Dhaka.

Marmot M and R Wilkinson, 2005. Social determinants of health: Oxford University Press, Oxford.

Ministry of Health and Family Welfare (MOHFW), Bangladesh, Partnership for Maternal, Newborn \& Child Health, WHO, World Bank and Alliance for Health Policy and Systems Research, 2015. Success Factors for Women's and Children's Health, Bangladesh. Available: http://www.who.int/pmnch/successfactors/en/index2.html

MOHFW: Health and Population Sector Programme. 1998, Ministry of Health and Family Welfare,Dhaka.

MOHFW: National Health Policy. 2000, Ministry of Health and Family Welfare,Dhaka.

Nagel SS, ed.,1999. Policy analysis methods, Nova Science Publication Incorporated, New York.

Nasreen H, 2006. Safe Motherhood Promotion Project in Narsingdi District: Baseline Survey, 2006: Research and Evaluation Division, BRAC in cooperation with Japan International Cooperation Agency, Bangladesh.

Nasreen H, SM Ahmed, HA Begum and K Afsana, 2007. Maternal, Neonatal and Child Health Programmes in Bangladesh. Review of good practices and lessons learned. Dhaka: Research and Evaluation Division, BRAC. Research Monograph Series No.32.

National Institute of Population Research and Training (NIPORT), ORC Macro, Johns Hopkins University and ICDDR,B. 2003. Bangladesh Maternal Health Services and Maternal Mortality Survey 2001. NIPORT, ORC Macro, Johns Hopkins University, and ICDDR,B. Dhaka, Bangladesh and Calverton, Maryland (USA)

Osman FA, 2004. Policy making in Bangladesh: a study of the health policy process: AH Development Publishing House, Dhaka, Bangladesh.

Osman FA, 2008. Health policy, programmes and system in Bangladesh achievements and challenges. South Asian Survey, Sept; 15(2), 263-288.

Paul BK and DJ Rumsey, 2002.Utilization of health facilities and trained birth attendants for childbirth in rural Bangladesh: an empirical study. Soc. Sci. Med., 54: 1755-1765.

Pogge T, 2004. The first united nations millennium development goal: a cause for celebration? J. Hum. Dev., 5: 377-397.

Rahman SA, JO Parkhurst and C Normand, 2003. Maternal Health Review Bangladesh. Policy Research Unit Ministry of Health and Family Welfare Bangladesh, Dhaka, Bangladesh.

Rashid S,Y Savchenko and N Hossain,2005. Public health and governance: the experience of Bangladesh and Ukraine. Q. Rev. Econ. Finance, 45: 460-475.

Rob U and G Cernada,1992.Fertility and family planning in Bangladesh. J. Fam. Welf., 38: 53-64.

Ronsmans C, ME Chowdhury, M Koblinsky and A Ahmed, 2010. Care seeking at time of childbirth, and maternal and perinatal mortality in Matlab, Bangladesh. Bull. World Health Organ., 88: 289-296.

Silverman JG, MR Decker, J Gupta, N Kapur, A Raj and RT Naved, 2009. Maternal experiences of intimate partner violence and child morbidity in Bangladesh: evidence from a national Bangladeshi sample. Arch. Pediatr. Adolesc. Med., 163: 700-705.

Ssengooba F, SA Rahman, C Hongoro, E Rutebemberwa, A Mustafa, T Kielmann and B McPake, 2007. Health sector reforms and human resources for health in Uganda and Bangladesh: mechanisms of effect. Hum. Resour. Health, Feb 1; 5(1), 3.

Vian T, 2008. Review of corruption in the health sector: theory, methods and interventions. Health policy and plan., Mar 1; 23: 83-94.

WHO, 1999. Health 21: the health for all policy framework for the WHO European region. Available: https://www.cabdirect.org/cabdirect/abstract/19992006386

WHO, 2004. Skilled birth attendance: review of evidence in Bangladesh. Available: http://www.who.int/bulletin/volumes/86/4/07-042754/en/. 